\title{
Local Excitatory Network and NMDA Receptor Activation Generate a Synchronous and Bursting Command from the Superior Colliculus
}

\author{
Yasuhiko Saito $^{1,2}$ and Tadashi Isa ${ }^{1}$ \\ ${ }^{1}$ Department of Integrative Physiology, National Institute for Physiological Sciences, Myodaiji, Okazaki 444-8585, Japan, and ${ }^{2}$ Department of Physiology, \\ Gunma University School of Medicine, Maebashi, Gunma 371-8511, Japan
}

\begin{abstract}
The generation of bursting spike activity in the deeper layers of the superior colliculus (SC) is a critical determinant of decision making in the initiation of orienting behaviors, such as saccades. The bursting activity exhibits a typical threshold effect that may arise from a nonlinear signal amplification process in the deeper layers of the SC. We used whole-cell patch-clamp recordings in rat SC slices to investigate the neuronal mechanism underlying the generation of such bursting activity. We found that (1) neurons in the intermediate gray layer [stratum griseum intermediale (SGI)] produce a prolonged bursting response when released from $\mathrm{GABA}_{\mathrm{A}}$ receptor-mediated inhibition, (2) this $\mathrm{GABA}_{\mathrm{A}}$ inhibition may partially arise from inhibitory interneurons within the SGI that are driven synaptically by glutamatergic excitatory inputs to the SC, (3) the bursting is not the result of the intrinsic membrane properties of individual SC neurons but is instead produced by local circuits within the SGI, (4) the bursting is mediated by activation of NMDA receptors, and (5) the bursting can be synchronous among SGI neurons. These results suggest that activation of a local excitatory network within the deeper layers of the $\mathrm{SC}$ and NMDA receptor-dependent synaptic transmission after release from $\mathrm{GABA}_{\mathrm{A}}$ inhibition are fundamental mechanisms that may explain the nonlinear signal amplification process in the deeper layers of the SC.
\end{abstract}

Key words: superior colliculus; presaccadic burst; deeper layers; NMDA receptors; slice; rat; patch clamp

\section{Introduction}

The mammalian superior colliculus (SC) is a brainstem center that controls the initiation of orienting behaviors, including saccadic eye movements toward an object that has attracted the subject's attention (Wurtz and Albano, 1980; Sparks, 1986; Dean et al., 1989). Neurons in the deeper layers of the SC [stratum griseum intermediale (SGI) and stratum griseum profundum] exhibit high-frequency burst firings preceding saccades (presaccadic bursts), and these bursts may trigger the downstream saccade generator circuits in the brainstem and command saccade vectors (Schiller and Koerner, 1971; Schiller and Stryker, 1972; Wurtz and Goldberg, 1972; Sparks et al., 1976, 2000; Sparks and Mays, 1980; Munoz and Wurtz, 1995). When repetitive electrical stimulation of various stimulus strengths is applied to the deeper layers of the SC, the induction of saccades exhibits a typical threshold effect (Robinson, 1972; Schiller and Stryker, 1972). This suggests that the deeper layers and their related structures include a neuronal mechanism that somehow enables nonlinear

\footnotetext{
Received 0ct. 18, 2002; revised April 28, 2003; accepted May 9, 2003.

This work was supported by grants from the Ministry of Education, Culture, Sports, Culture, Science and Technology of Japan, Core Research for Evolutional Science and Technology of Japan Science and Technology Corporation, Daiko Foundation, Naito Memorial Foundation, Mitsubishi Foundation (T.I.), and Japan Society for the Promotion of Science Grant-in Aid for Encouragement of Young Scientists (Y.S.). We thank Dr. Y. Kobayashi for discussions, Dr. T. Endo for partial participation in the experiments, Dr. S. Ozawa for continuous encouragement, and M. Seo and J. Yamamoto for technical assistance.

Correspondence should be addressed to Dr. Tadashi Isa, Department of Integrative Physiology, National Institute for Physiological Sciences, Myodaiji, Okazaki 444-8585, Japan. E-mail: tisa@nips.ac.jp.

Copyright $\odot 2003$ Society for Neuroscience $\quad$ 0270-6474/03/235854-11\$15.00/0
}

signal amplification. Several studies have suggested that the generation of bursting activity in the deeper layers of the SC is a critical determinant of decision making in the initiation of saccades after target selection or prediction (Glimcher and Sparks, 1992; Dorris et al., 1997). Hence, exploring the cellular and synaptic mechanisms underlying the generation of bursts in the deeper layers of SC may lead to a better understanding of the fundamental neuronal mechanisms involved in the decisionmaking process within the brain.

It has been demonstrated that the deep layers of the SC contain saccade-related tectal long-lead burst neurons (TTLBs) that discharge high-frequency bursts before a saccade. TTLBs emit recurrent collaterals terminating within the SC (Moschovakis et al., 1988b), and their descending axons form part of the predorsal bundle that most likely consists of glutamatergic fibers (Moschovakis et al., 1988b; Horn et al., 1994). In light of these findings, Moschovakis et al. (1988b) proposed that saccade-related bursts are caused by lateral excitatory interactions among TTLBs. Although the lateral excitatory interactions that might occur within the SC local circuits have been evaluated by means of a neural network model (Bozis and Moschovakis, 1998), actual physiological evidence has not been obtained. Furthermore, whether the bursts occur in local circuits within the SC and what cellular mechanisms underlie burst generation remain open questions. To answer these questions, we explored the fundamental properties of the SC local circuits in slice preparations, in which the SC is isolated from other brain structures. 
Although previous morphological studies have indicated the existence of interlaminar connections from the superficial gray layer [stratum griseum superficiale (SGS)] to the SGI (Grantyn et al., 1984; Mooney et al., 1988; Moschovakis et al., 1988a; Rhoades et al., 1989; Behan and Appell, 1992; Hall and Lee, 1993; Lee and Hall, 1995), in vitro experiments using the whole-cell patchclamp technique in SC slice preparations have succeeded in demonstrating the physiological evidence for the existence of the excitatory pathway from the SGS to SGI (Lee et al., 1997; Isa et al., 1998). After application of the $\mathrm{GABA}_{\mathrm{A}}$ receptor antagonist bicuculline (Bic), excitatory transmission from the optic tract (OT) and SGS to SGI was much enhanced, and SGI neurons exhibited burst firings that occurred in an all-or-none manner at threshold stimulus intensity (Isa et al., 1998). Previous in vivo studies have shown that neurons in the deeper layers of the SC are inhibited by GABAergic neurons located in the substantia nigra pars reticulata (SNr) (Karabelas and Moschovakis, 1985; Moschovakis et al., 1988a). These GABAergic SNr neurons are tonically active, and they pause just before and during saccade onset (Hikosaka and Wurtz, 1983a,b,c). A similar pattern of inhibition may be mediated by fixation neurons in the rostral pole of the SC (rSC) via local inhibitory neurons (Munoz and Wurtz, 1993; Meredith and Ramoa, 1998; Munoz and Istvan, 1998). These findings indicate that saccadic burst neurons in the SC are released from tonic inhibition during presaccadic bursts. Thus, our in vitro model for inducing bursts in SGI neurons in the presence of a GABA $\mathrm{A}$ receptor antagonist could be used to elucidate the neuronal mechanism responsible for premovement bursts in vivo. The present results show that both the local excitatory network and NMDA receptor-dependent synaptic transmission are essential for generation of bursting responses in SGI neurons. Preliminary data have been presented in abstract form (Isa et al., 1999).

\section{Materials and Methods}

The procedures used in our animal experiments followed the guidelines for animal experimentation approved by the Animal Research Committee of the Okazaki National Institutes.

Frontal slices of the SC (400 $\mu \mathrm{m}$ in thickness) were obtained from young (17-22 postnatal days) and adult (7-8 weeks after birth) Wistar rats using procedures similar to those described previously (Isa et al., 1998; Saito and Isa, 1999, 2000). A total of 106 slices from 32 young animals and 23 slices from 6 adult animals were used in the present experiments. Decapitation was performed under deep ether or isoflurane anesthesia (adequacy was judged by the absence of reflex movements to toe pinches). The slices were incubated in oxygenated standard Ringer's solution containing (in $\mathrm{mM}$ ): $145 \mathrm{NaCl}, 2.5 \mathrm{KCl}, 2 \mathrm{CaCl}_{2}, 1 \mathrm{MgCl}_{2}, 5$ HEPES, and 10 glucose, for $>1 \mathrm{hr}$ before recording began. After incubation, one slice was placed in a submersion-type recording chamber under continuous superfusion with oxygenated standard Ringer's solution. Whole-cell patch-clamp recordings were obtained from selected neurons in SGS and SGI. Patch pipettes were filled with an internal solution containing (in mM): $140 \mathrm{~K}$-gluconate, $20 \mathrm{KCl}$ (for current-clamp recordings) or $150 \mathrm{Cs}$-gluconate (for voltage-clamp recordings), 0.2 EGTA, 2 $\mathrm{MgCl}_{2}, 2 \mathrm{Na}_{2} \mathrm{ATP}, 0.3 \mathrm{NaGTP}, 10$ HEPES, and 0.1 spermine, $\mathrm{pH}$ 7.3. Biocytin $(5 \mathrm{mg} / \mathrm{ml})$ was added to the internal solution to verify the location and morphology of the recorded neurons. In some experiments, we added lidocaine $N$-ethyl bromide quarternary salt (QX314) to the intracellular solution to block the generation of action potentials. When a high concentration of bis-(o-aminophenoxy)- $N, N, N^{\prime}, N^{\prime}$-tetra-acetic acid (BAPTA) was to be applied intracellularly, K-gluconate was replaced with $30 \mathrm{~mm} 4 \mathrm{~K}$-BAPTA. The resistance of the recording pipettes was 3-7 $\mathrm{M} \Omega$ in the bath solution, and the series resistance during recording was $10-30 \mathrm{M} \Omega$. Whole-cell current- and voltage-clamp recordings were performed at a temperature of $30-32^{\circ} \mathrm{C}$ using an EPC-7 or EPC-9 patchclamp amplifier (Heka, Lambrecht, Germany). Electrical stimulation, whether of optic fibers or the superficial layer, was applied as cathodal square-wave pulses of $200 \mu$ sec pulse duration at 10 sec intervals using a concentric bipolar electrode (Clark Electromedical Instruments, Pangbourne, UK). For stimulation of optic fibers, we placed the stimulation electrode in the most lateral portion of the optic layer (LSO), in which the optic fibers form a bundle (Isa et al., 1998). When the connection from the superficial to the intermediate layer was to be investigated, the stimulation electrode was placed in the superficial gray layer (SGS) directly dorsal to the recorded SGI neuron. Synaptic responses were usually recorded five times at the same stimulus strength. Pharmacological agents, except for 6-cyano-7-nitroquinoxaline-2,3-dione (CNQX), were dissolved in distilled water to make a concentrated stock solution (1000X the final concentration) (see Results), and diluted to the final concentration in the external solution just before the experiments. CNQX was dissolved in dimethylsulfoxide to make a concentrated stock solution. To obtain stable recordings after the application of drugs, we waited until 1 min after the complete exchange of the bath solution in the recording chamber and then started recording. Membrane potentials were corrected for junction potentials of $-10 \mathrm{mV}$. Voltage and current signals were filtered at $3 \mathrm{kHz}$. Voltage-clamp data and current-clamp recordings with action potentials were sampled at $10-20 \mathrm{kHz}$, and current-clamp recordings of subthreshold membrane potentials without spikes were at 1-10 kHz. Data were acquired and stored using pClamp6 (Axon Instruments, Foster City, CA) or Pulse/Pulsefit software (Heka), and off-line analysis was performed using Axograph (Axon Instruments), Igor Pro (WaveMetrics, Lake Oswego, OR), and Matlab (MathWorks, Natick, MA) software. After completion of the recordings, patch pipettes were carefully detached from the recorded cells, and the slices were fixed with $4 \%$ paraformaldehyde in $0.05 \mathrm{~m}$ phosphate buffer, $\mathrm{pH} 7.4$, for $2-4 \mathrm{~d}$ at $4^{\circ} \mathrm{C}$. The procedures used for visualization of biocytin-filled neurons have been detailed previously (Isa et al., 1998; Saito and Isa, 1999). CNQX, QX314, 4K-BAPTA, biocytin, 2-(3-carboxypropyl)-3-amino-6(4-methoxyphenyl)-pyridazinium bromide (SR95531), and (-)bicuculline methobromide were purchased from Sigma (St. Louis, MO), D-2-amino-5-phosphonovalerate (D-APV) was purchased from Research Biochemicals International (Natick, MA), and others drugs were purchased from Wako Pure Chemical (Osaka, Japan).

\section{Results}

\section{Bursting responses in SGI neurons}

Figure 1 shows simultaneous whole-cell current-clamp recordings from a pair of SGS and SGI neurons located along the dorsoventral axis of the SC (Fig. 1C). In control solution, stimulation of LSO induced EPSPs in both neurons (Fig. 1A), the latency being constant at $2.7 \mathrm{msec}$ in the SGS neuron but variable at between 6.6 and $12.7 \mathrm{msec}$ in the SGI neurons. These results are consistent with our previous finding that stimulation of LSO induces monosynaptic EPSPs in SGS neurons, but oligosynaptic EPSPs in SGI neurons that are mediated by neurons in SGS or in the optic layer [stratum opticum (SO)] (Isa et al., 1998). When 10 $\mu \mathrm{M}$ Bic was added to the extracellular solution in the SGS neuron, the EPSP was enhanced, and a few action potentials were induced (Fig. $1 B$, top trace), whereas in the SGI neuron, the EPSP was markedly enhanced, and trains of action potentials were generated (middle and bottom traces). This result-a moderate enhancement of EPSPs in SGS neuron and a marked enhancement in SGI neuron-was confirmed in seven neuron pairs. The duration of the EPSPs before and after application of Bic was measured in six of these pairs (in the other, it was not measured, because the fluctuation in the EPSPs was too large after Bic application). The EPSP durations in SGS neurons before and after Bic application were $97.3 \pm 22.3 \mathrm{msec}$ and $149.5 \pm 38.1 \mathrm{msec}$ (mean \pm SEM), respectively, whereas those in SGI neurons were $86.8 \pm 70.1 \mathrm{msec}(n=2$; the other four neurons did not exhibit EPSPs) and $1490.6 \pm 531.6 \mathrm{msec}(n=6)$, respectively. The average instantaneous firing frequency of SGI neurons in response to stimulation of the LSO at below $100 \mu \mathrm{A}$ after application of Bic, 


\section{A Control}
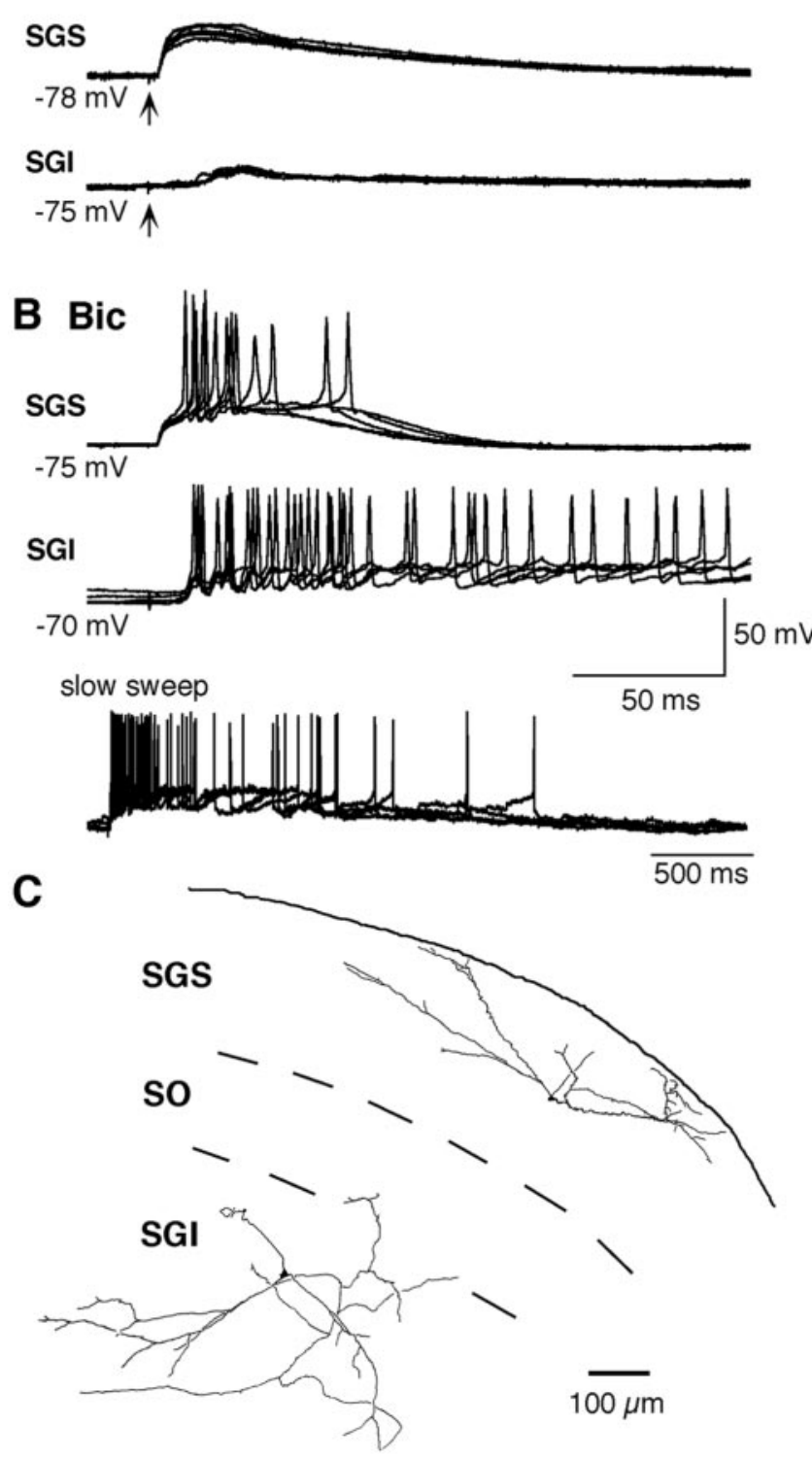

Figure 1. Simultaneous recordings from a pair of SGS and SGI neurons. Five traces are superimposed. $A$, Synaptic responses in SGS (top traces) and SGI (bottom traces) neurons to stimulation of LSO (arrow, $100 \mu \mathrm{A}$ ) in control solution. B, Synaptic responses in SGS (top traces) and SGI (middle and bottom traces) neurons after application of $10 \mu \mathrm{M}$ Bic. The bottom traces are slower sweep records of the middle ones. C, Drawing of biocytin-filled SGS and SGI neurons visualized after the recordings.

taken as the average of the three interspike intervals after the first spike, ranged from 71.6 to $240.8 \mathrm{~Hz}(115.7 \pm 21.9 \mathrm{~Hz}$, mean \pm SEM; $n=7)$. These results indicate that release from $\mathrm{GABA}_{\mathrm{A}}$ receptor-mediated inhibition enables the SGI neuron to generate long-lasting depolarization and repetitive firing.

Intracellular staining with biocytin revealed that the SGS and SGI neurons illustrated in Figure 1 were horizontal and multipolar cells, respectively (Fig. 1C). Among the seven pairs of SGS and SGI neurons, five SGS and six SGI neurons were classified morphologically (one narrow-field vertical cell, two wide-field vertical cells, and two horizontal cells in SGS, and four multipolar, one fusiform, and one pyramidal-shaped cells in SGI). Morphologic analysis suggested that the SGS neurons exhibiting a moderate enhancement of EPSPs in the presence of Bic included some

\section{A Control}
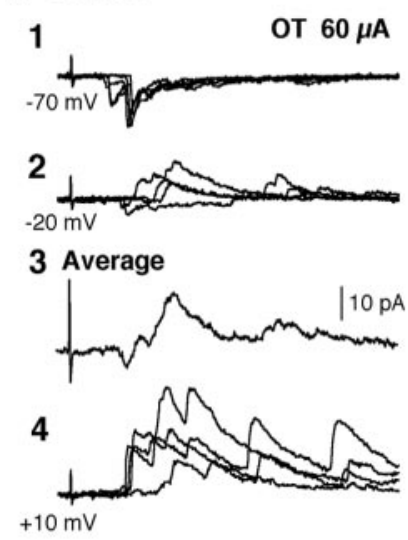

B CNQX + D-APV
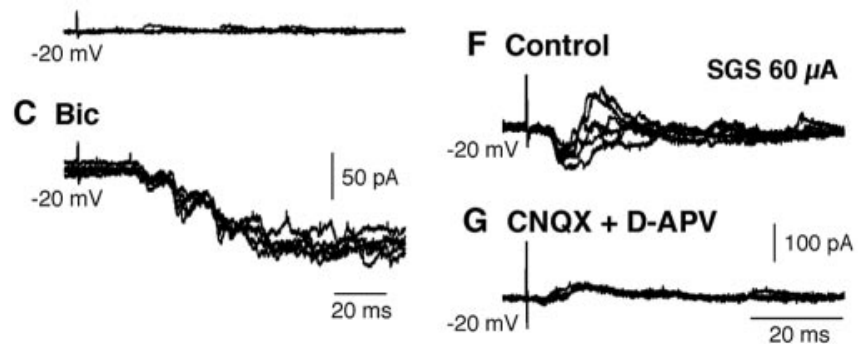

Figure 2. A, Synaptic currents in an $\mathrm{SGI}$ neuron induced by $\mathrm{LSO}$ stimulation and recorded at different holding potentials $(1,-70 \mathrm{mV} ; 2,-20 \mathrm{mV} ; 3$, average of traces in $2 ; 4,+10 \mathrm{mV})$ in control solution. $B$, Synaptic currents in the same neuron as in $A$, this time recorded at a holding potential of $-20 \mathrm{mV}$ in the presence of $5 \mu \mathrm{m}$ CNQX plus $50 \mu \mathrm{m} \mathrm{D}-A P V$. C, Synaptic currents in the same neuron in $A$ recorded at a holding potential of $-20 \mathrm{mV}$ in the presence of $10 \mu \mathrm{m}$ Bic. $D$, Synaptic currents in an SGI neuron induced by SGS stimulation and recorded at different holding potentials $(1,-60 \mathrm{mV} ; 2,-20 \mathrm{mV} ; 3$, average of traces in 2) in control solution. E, Synaptic currents in the same neuron as in $D$ recorded at a holding potential of $-20 \mathrm{mV}$ in the presence of $5 \mu \mathrm{M}$ CNQX plus $50 \mu \mathrm{m}$ D-APV. F, Synaptic currents in another SGI neuron induced by SGS stimulation and recorded at a holding potential of $-20 \mathrm{mV}$ in control solution. G, Synaptic currents in the same neuron as in $F$ recorded at a holding potential of $-20 \mathrm{mV}$ in the presence of $5 \mu \mathrm{m}$ CNQX plus $50 \mu \mathrm{m}$ D-APV.

putative output neurons projecting to SGI (narrow-field and wide-field vertical cells) (Mooney et al., 1988; Hall and Lee, 1993; Lee and Hall, 1995; Isa et al., 1998; Özen et al., 2000).

Local inhibitory circuits within the SC

The marked enhancement of EPSPs in SGI neurons under Bic indicates that signal transmission via pathways from the OT to SGI is somehow inhibited by GABAergic neurons. To explore the inhibitory mechanism, we investigated whether GABAergic inhibition curtails the early excitation after stimulation of OT-SGI pathways. For this purpose, we recorded inhibitory postsynaptic responses in SGI neurons upon LSO (Fig. 2, $A-C$ ) and SGS stimulation $(D-G)$. We used voltage-clamp mode to obtain a clearer dissociation of inhibitory responses from excitatory ones (see below). In control solution, with the membrane potential held at $-70 \mathrm{mV}$, inward postsynaptic currents of variable onset, suggesting an oligosynaptic origin (latency, 12.1-14.7 msec), were induced by LSO stimulation (Fig. 2A1). At $-20 \mathrm{mV}$, which is between the reversal potentials for IPSCs $(-47 \mathrm{mV})$ and EPSCs $(\sim 0$ $\mathrm{mV}$ ), the induced inward postsynaptic currents were followed by outward synaptic currents (Fig. 2 A2,3). However, at $+10 \mathrm{mV}$, all of the postsynaptic currents were outward (Fig. 2A4). All of these synaptic currents were abolished by the application of $5 \mu \mathrm{M}$ CNQX plus $50 \mu \mathrm{M}$ D-APV (Fig. $2 B$ ). When CNQX and D-APV 
were washed out and Bic was applied, the same stimulation induced only inward synaptic currents at $-20 \mathrm{mV}$ (Fig. 2C). In all six of the SGI neurons tested, similar results were obtained. These results suggest that LSO stimulation induces polysynaptic GABAergic IPSCs in addition to the preceding oligosynaptic glutamatergic EPSCs. Furthermore, they suggest that, after the LSO stimulation, the GABAergic inhibitory neurons terminating on SGI neurons are activated synaptically via glutamatergic excitatory inputs.

Our previous study suggested that excitatory inputs from OT to SGI neurons are mediated via SGS and SO neurons (Isa et al., 1998). It is well known that the SC contains a high density of GABAergic neurons, the density of which is highest in the superficial layers and relatively low in the deeper layers (Ottersen and Storm-Mathisen, 1984; Mize, 1988; Mize et al., 1991). Therefore, it is meaningful to ask whether it is SGS or SGI GABAergic neurons that mediate the polysynaptic IPSCs/IPSPs that are induced in SGI neurons after LSO (OT) stimulation. To answer this question, we investigated the effects of stimulation of SGS sites dorsal to the cells from which we recorded. In control solution, with the membrane potential held at $-60 \mathrm{mV}$, inward postsynaptic currents with a fixed onset, suggesting a monosynaptic origin (latency, $5.6 \mathrm{msec}$ ), were induced by SGS stimulation (Fig. 2D1). At $-20 \mathrm{mV}$, the inward postsynaptic currents were followed by outward postsynaptic currents (Fig. 2D2,3). All of the postsynaptic currents induced by SGS stimulation were abolished by application of $5 \mu \mathrm{M}$ CNQX plus $50 \mu \mathrm{M}$ D-APV in this particular case (Fig. $2 E$ ). These results suggest that the IPSCs induced by SGS stimulation were polysynaptic (i.e., the GABAergic neurons that induced IPSCs in the recorded SGI neurons were synaptically excited by glutamatergic inputs induced by the stimulation). Of the nine SGI neurons recorded, eight received polysynaptic IPSCs as shown in Figure 2D. Only in one SGI neuron did monosynaptic IPSCs remain under CNQX plus D-APV, although their amplitude was much smaller than that of the oligosynaptic ones (Fig. 2, compare $F, G$ ). This suggests that stimulation of the SGS usually does not activate inhibitory SGS neurons establishing direct connections with SGI neurons. To judge from previous anatomical and physiological observations suggesting that the interlaminar connections from the SGS to SGI are organized mostly in a columnar-like manner (Moschovakis et al. 1988a; Rhoades et al., 1989; Behan and Appell, 1992; Lee and Hall, 1995; Lee et al., 1997), it is highly likely that SGS stimulation synaptically activates inhibitory neurons in the deeper layers, and that these induced $\mathrm{GABA}_{\mathrm{A}}$ receptor-mediated IPSCs in the recorded SGI neurons (see Discussion). These results suggest that the inhibitory neurons in the deeper layers induce feedforward and/or recurrent inhibition in SGI neurons after both OT and SGS stimulation. The IPSPs resulting from such an inhibitory mechanism may curtail EPSPs and prevent prolongation of excitation in SGI neurons.

In the presence of $5 \mu \mathrm{M} C N Q X$ plus $50 \mu \mathrm{M}$ D-APV, spontaneous postsynaptic currents, which were reversed at approximately $-40 \mathrm{mV}$, were observed in SGI neurons (Fig. 3A). These currents were abolished by the application of $10 \mu \mathrm{M}$ Bic (Fig. $3 B$ ) and recovered after washout of $\mathrm{Bic}(C)$, indicating that they were IPSCs mediated by $\mathrm{GABA}_{\mathrm{A}}$ receptors. Similar results were obtained in SGI neurons even when the SC slice was separated from the ventrally located tegmentum $(n=6)$. These results indicate that SGI neurons receive tonic inhibition from GABAergic interneurons in the SC even in in vitro preparations.
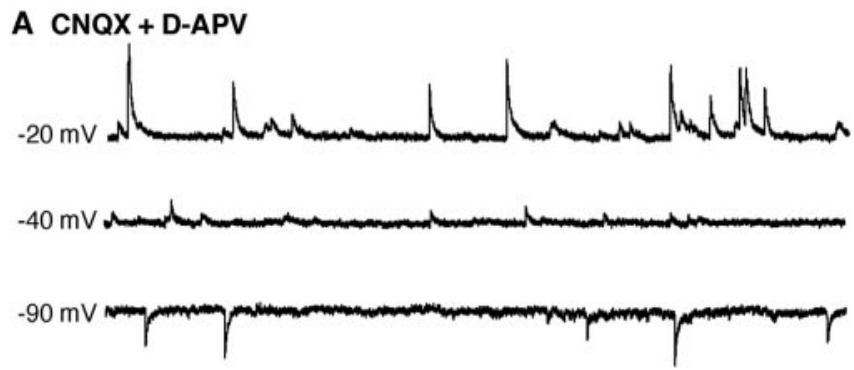

\section{B CNQX + D-APV + Bic}

$-20 \mathrm{mV}$

\section{CNQX + D-APV (Bic wash)}

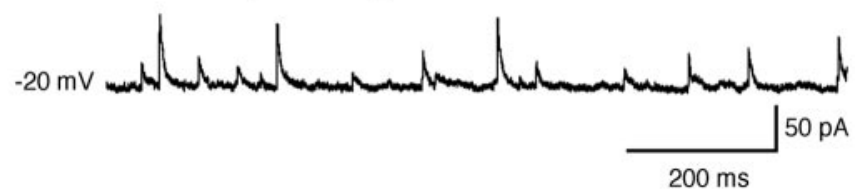

Figure 3. Spontaneous postsynaptic currents in an SGI neuron recorded in the presence of 5 $\mu \mathrm{m}$ CNQX plus $50 \mu \mathrm{m}$ D-APV.A, Spontaneous postsynaptic currents recorded at different holding potentials (values given at left). $B$, Spontaneous postsynaptic currents in the presence of $5 \mu \mathrm{m}$ CNQX plus $50 \mu \mathrm{m}$ D-APV, and $10 \mu \mathrm{m}$ Bic. C, Spontaneous postsynaptic currents recorded after washing out Bic.

\section{Bursting responses in SGI neurons are not caused by their} intrinsic properties

We next determined whether the generation of long-lasting depolarization and repetitive firing in SGI neurons was caused by the intrinsic property of individual SGI neurons. For this purpose, we examined the input-output relationship for the firing responses to depolarizing current pulses and that for the synaptic responses to LSO stimulation. Because Bic has been shown to block SK-type calcium-activated potassium channels (Johnson and Seutin, 1997; Debarbieux et al., 1998; Khawaled et al., 1999), we used another $\mathrm{GABA}_{\mathrm{A}}$ receptor antagonist, SR95531, in this experiment. Figure $4, A$ and $B$, shows the firing responses induced in an SGI neuron of the regular-spiking type-a type that makes up the major subpopulation of SGI neurons (Saito and Isa, 1999) - by current pulses (400 msec in duration) in control solution and in a solution containing $10 \mu \mathrm{M}$ SR95531. As expected from the fact that SR95531 does not affect afterhyperpolarization (Seutin et al., 1997), plots of the number of action potentials against the amplitude of the injected current (Fig. 4C) revealed that the former was the same increasing function of the latter when the neuron was bathed either in the control solution or a solution containing SR95531. Figure 4, $D$ and $E$ (the synaptic responses of the same neuron as in $A$ and $B$ to LSO stimulation) shows that, in control solution, only a few action potentials were induced even by an extremely strong stimulus $(D)$, whereas longlasting depolarization and repetitive firing was induced at above a certain stimulus intensity under SR95531 (E). The difference between control solution and SR95531 in the input-output relationship of the SGI neurons was obvious (Fig. $4 F$ ). The plot revealed that, in the presence of SR95531, the number of action potentials increased abruptly above a particular threshold value of stimulus strength.

In contrast to SGI neurons, SGS neurons showed no such input-output relationship in response to LSO stimulation. In neurons exhibiting a linear-like relationship between number of 
A Control

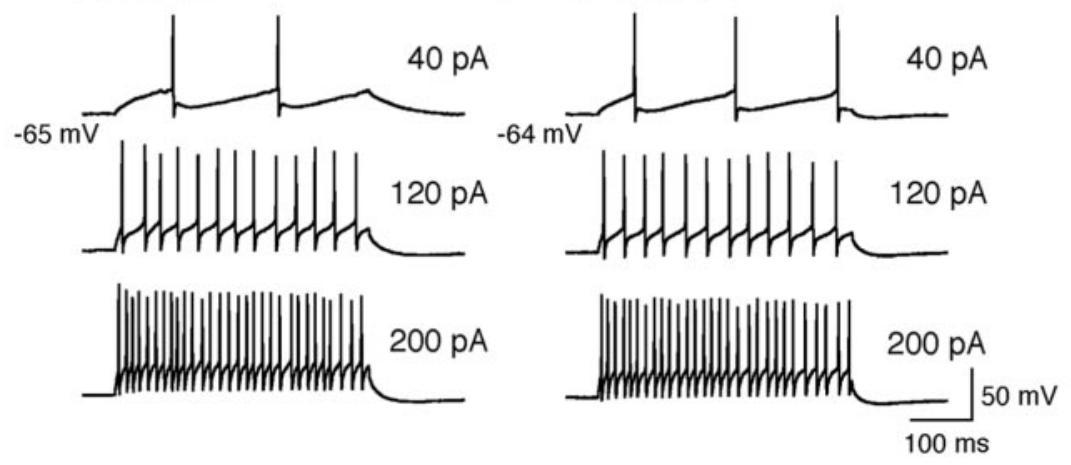

D Control
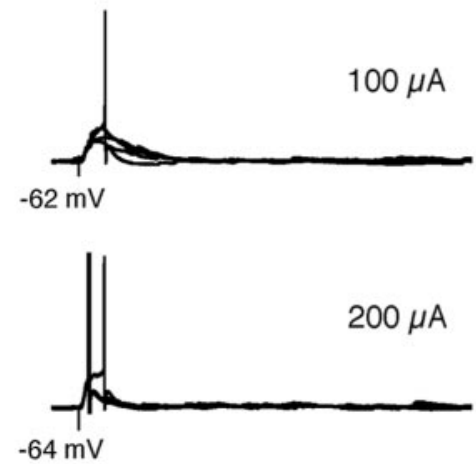

B SR95531

E SR95531

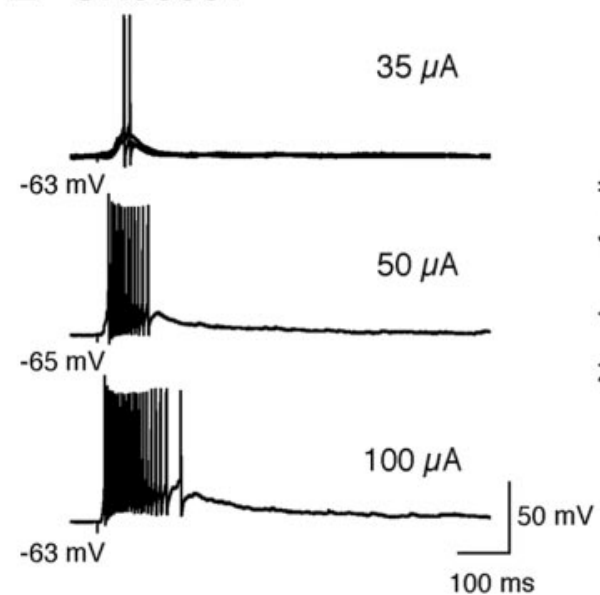

C

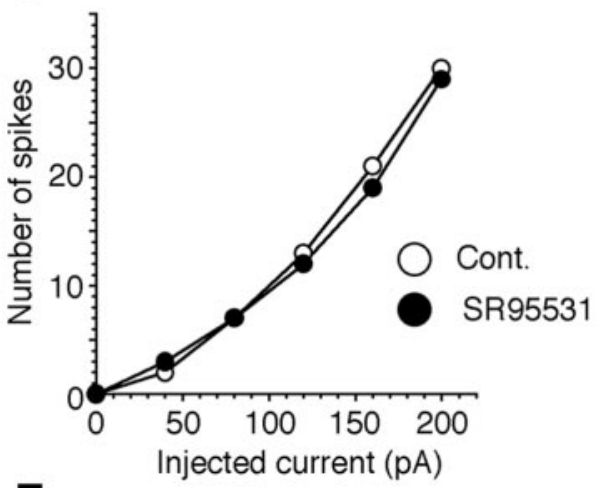

F

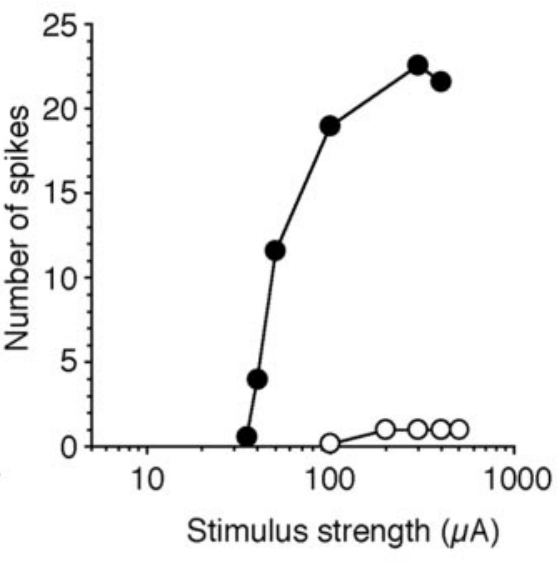

Figure 4. Input- output relationships for intrinsic and synaptic properties of an SGI neuron. $A$ and $B$, Firing responses in an $S G I$ neuron induced by depolarizing current pulses in control solution and under $10 \mu \mathrm{M} S R 95531$, respectively. C, Plots of number of action potentials against amplitude of injected currents (open circle, control; closed circle, SR95531). D and $E$, Synaptic responses to LSO stimulation in control solution and under $10 \mu \mathrm{m}$ SR95531, respectively. Five traces are superimposed in $D$ and in top panel in $E$. F, Plots of number of action potentials against stimulus strength (symbols as in C).

action potentials and injected currents, only a small number of action potentials were induced even when a strong stimulus was applied in the presence of SR95531 (Fig. 5B). Although a few SGS neurons exhibited repetitive firing under SR95531, these neurons did not exhibit a depolarization as long lasting as that seen in SGI neurons (data not shown) (Özen et al., 2000).

Figure 5 shows population data obtained from seven SGS (Bic, $n=5$; SR95531, $n=2$ ) and seven SGI neurons (Bic, $n=3$; SR95531, $n=4$ ) before and after application of a $\mathrm{GABA}_{\mathrm{A}}$ receptor antagonist. Examination of the intrinsic firing responses to depolarizing current pulses revealed that each type of neuron (SGS or SGI) exhibited similar linear-like input-output relationships between control solution and under a $\mathrm{GABA}_{\mathrm{A}}$ receptor antagonist (Fig. $5 A, C$ ). However, application of a $\mathrm{GABA}_{\mathrm{A}}$ receptor antagonist did slightly increase the intrinsic firing rate in some SGS and SGI neurons (Fig. 5A,C). Likewise, the number of action potentials induced by LSO stimulation in SGS neurons increased slightly after application of a $\mathrm{GABA}_{\mathrm{A}}$ receptor antagonist (Fig. 5B), whereas synaptic responses in SGI changed drastically, with most SGI neurons showing an abrupt increase in the number of action potentials above a particular stimulus strength (Fig. $5 D)$. These results suggest that the long-lasting depolarization and repetitive firing seen in SGI neurons was attributable not to the intrinsic properties of individual neurons but most likely to synaptic mechanisms inherent to SC local circuits.

\section{Bursting mechanism is confined to a local circuit within} the SGI

To test whether the neuronal elements sufficient to produce longlasting depolarization and repetitive firing exist within the SGI, we punched out a small rectangular piece of SGI $(\sim 500 \mu \mathrm{m}$ dorsoventrally and $1 \mathrm{~mm}$ mediolaterally) and placed both the stimulating and recording electrodes in it (Fig. 6A). As exemplified in Figure $6 B$, neurons in the small piece produced only one action potential in control solution even when strong stimulation was applied. However, long-lasting depolarization and repetitive firing was induced after application of Bic (Fig. 6C), with the number of action potentials increasing abruptly above a particular stimulus intensity $(D)$ as shown above for intact SC slices. Of 19 SGI neurons examined in small pieces of SGI, 9 showed burst firing in response to local stimulation. Thus, even a small region of SGI is equipped with the neural elements needed to generate bursts.

\section{Burst activity in SGI neurons in adult rats}

All of the data presented above were obtained from young animals. To test whether long-lasting depolarization and repetitive firing can also be induced in adult animals, we recorded the synaptic responses of SGI neurons to LSO stimulation in SC slices obtained from young adult rats (7-8 weeks after birth) (Fig. 7A). Of a total of 23 SGI neurons recorded, 17 showed an enhance- 


\section{SGS neurons} Current injection A1

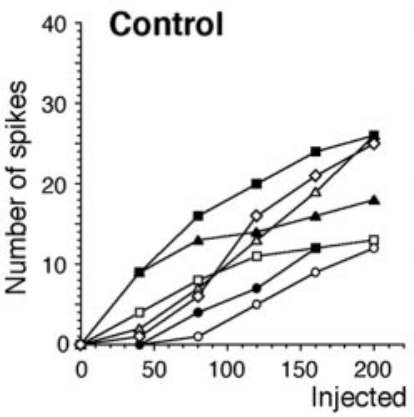

A2

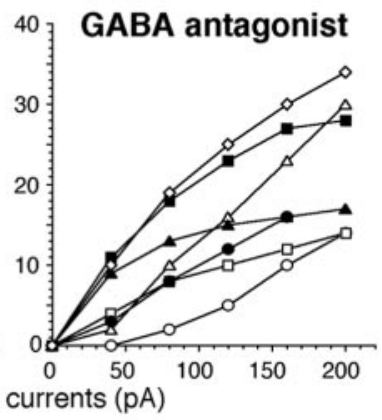

OT stimulation

B1

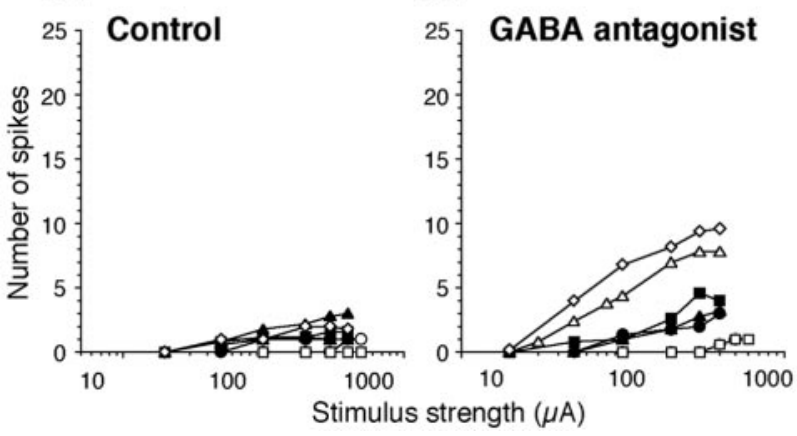

SGI neurons

Current injection

C1

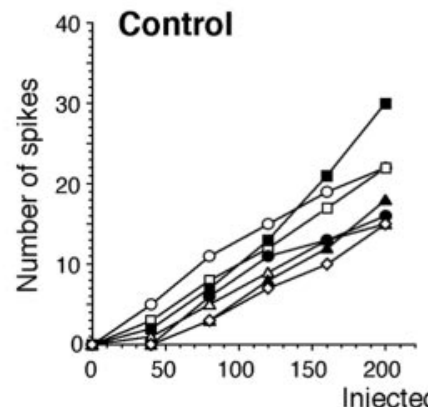

C2

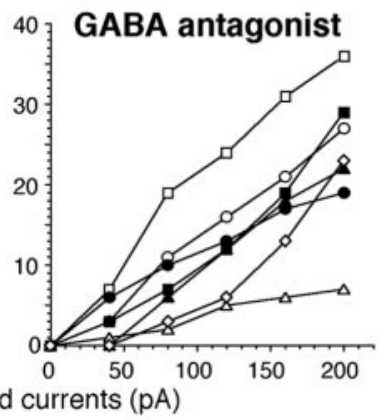

OT stimulation

D1

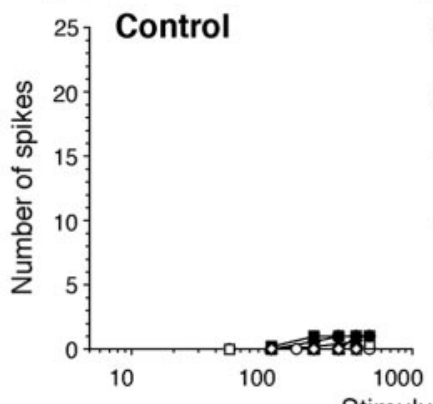

D2

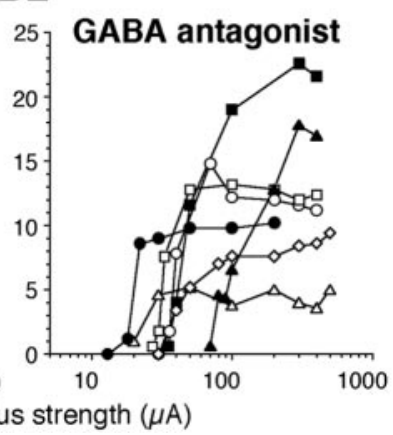

Figure 5. Input- output relationships for intrinsic and synaptic properties of $S G S$ ( $A$ and $B$ ) and $S G I$ ( $C$ and $D)$ neurons in control (1) and in the solution containing GABA antagonist ( 2 ). Individual symbols represent the plots obtained from individual neurons. Population data obtained from seven SGS neurons (Bic, $n=5$; SR95531, $n=2$ ) and seven SGI neurons (Bic, $n=3$; SR95531, $n=$ 4) are shown. Bic, $10 \mu \mathrm{m} ;$ SR95531, $10 \mu \mathrm{m}$.

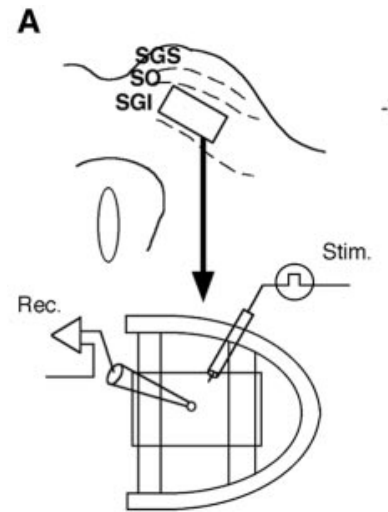

B Control

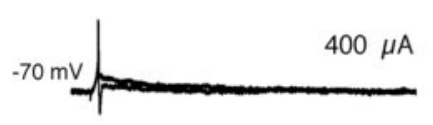

D
C Bic
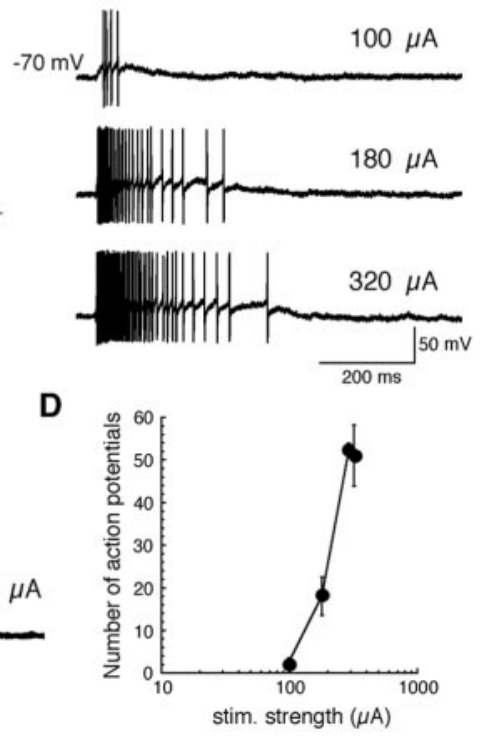

Figure 6. Implementation of nonlinear synaptic activity in local circuits within the SGI. $A$, Schematic illustration of a recording from a neuron in a small rectangular piece punched out from the SGI. Stim., Stimulating electrode; Rec., recording electrode. B, Synaptic response to stimulation within this piece in control solution. Five traces are superimposed. C, Synaptic response to stimulation within the piece of SGI in the presence of $10 \mu \mathrm{m}$ Bic. D, Relationship between number of action potentials and stimulus strength in the presence of Bic. Filled circles and error bars represent mean and SEM, respectively.

ment of EPSPs after application of $10 \mu \mathrm{M}$ Bic. In the presence of Bic, four SGI neurons showed long-lasting depolarization and repetitive firing consisting of $>10$ spikes (Fig. $7 A 1,2$ ), eight showed repetitive firing with a moderate number of spikes (three to eight spikes at a stimulus strength of 200-300 pA), and five showed enhanced EPSPs without spikes (data not shown). EPSPs could not be induced in six SGI neurons either in control solution or under Bic. These results confirmed that the long-lasting depolarization and repetitive firing seen under a $\mathrm{GABA}_{\mathrm{A}}$ receptor antagonist in young animals is also found in adults, although they may have been observed less frequently in the adult animals. However, we believe this is because damage to neurons during slice preparation and incubation is more serious in adult animals. Indeed, generation of burst firings in deeper-layer neurons in adult rats after application of a $\mathrm{GABA}_{\mathrm{A}}$ receptor antagonist has been verified in a recent in vivo study (Katsuta and Isa, 2003).

NMDA receptor-dependent mechanism for burst activity When $50 \mu \mathrm{M}$ D-APV was added to the extracellular solution, no long-lasting depolarization was observed in SGI neurons, and only a small fraction of the EPSP remained (Fig. $7 B$ ). Similar results were obtained from all six SGI neurons tested. This result indicates that the long-lasting depolarization in SGI neurons is dependent on synaptic transmission mediated by NMDA-type glutamate receptors. Such NMDA receptor-dependent burst activity was observed in adult animals also $(n=8)$ (Fig. 7A3,4).

Because NMDA receptor channels show a high $\mathrm{Ca}^{2+}$ permeability (MacDermott et al., 1986), we investigated the possibility that a calcium-dependent mechanism triggered by $\mathrm{Ca}^{2+}$ influx through NMDA receptors, such as a plateau-like depolarization 
A

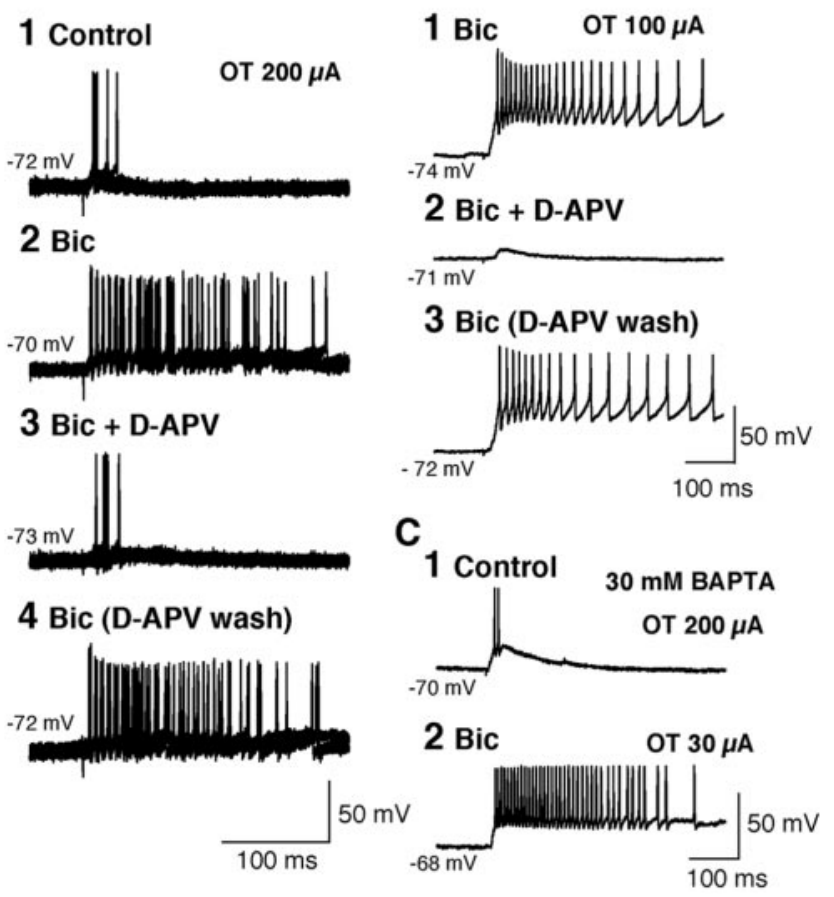

Figure 7. A, Synaptic response induced in an SGI neuron in an adult animal by stimulation of the LSO in control solution ( 1), after application of $10 \mu \mathrm{M} \mathrm{Bic} \mathrm{(2),} \mathrm{after} \mathrm{application} \mathrm{of} 10 \mu \mathrm{m} \mathrm{Bic}$ plus $50 \mu \mathrm{m}$ D-APV (3), and after washing out D-APV (4). Stimulus strength was $200 \mu \mathrm{A} . \mathrm{B}$, Synaptic response induced in an SGI neuron in a young animal by stimulation of LSO after application of $10 \mu \mathrm{M}$ Bic (1), after application of $10 \mu \mathrm{m}$ Bic plus $50 \mu \mathrm{M} \mathrm{D}-A P V(2)$, and after washing out D-APV (3). Stimulation strength was $100 \mu$ A. C, Synaptic response induced in an SGI neuron by stimulation of $L S O$ in control solution (1) and after application of $10 \mu \mathrm{M} \mathrm{Bic} \mathrm{(2).}$ The intracellular solution contained $30 \mathrm{~mm}$ BAPTA. Stimulus strength is given at right.

mediated by $\mathrm{Ca}^{2+}$-dependent nonselective cation channels (Partridge et al., 1994), is involved in the generation of the longlasting depolarization. We recorded synaptic responses induced in SGI neurons by LSO stimulation using an intracellular solution containing $30 \mathrm{~mm}$ BAPTA to chelate intracellular $\mathrm{Ca}^{2+}$. As shown in Figure $7 C$, long-lasting depolarization and repetitive firing was observed even under BAPTA. Of the seven SGI neurons tested, five showed long-lasting depolarization and burst firing, whereas two did not show action potentials either in control solution or in extracellular solution containing $10 \mu \mathrm{M} \mathrm{Bic}$ (although their EPSPs were enhanced by Bic). These results suggest that $\mathrm{Ca}^{2+}$-dependent mechanisms are not essential for the generation of long-lasting depolarization and repetitive firing in SGI neurons.

\section{Synchronization of adjacent SGI neurons after disinhibition}

Because the results described above suggest that burst firing in SGI neurons can be induced by processes existing within a local SGI circuit, we next performed simultaneous whole-cell recordings from a pair of SGI neurons separated by $<100 \mu \mathrm{m}$ in slices obtained from young animals (Fig. $8 \mathrm{~A}$ ). The direct synaptic connections between the two neurons were checked by recording current responses from one cell after a single or several action potentials had been evoked in the other cell by current injection. No apparent synaptic current was observed in the particular pair illustrated by Figure $8 B$, indicating that they were not in direct contact with each other. The membrane potentials of these neurons were stable in control solution (Fig. 8C1), but when $10 \mu \mathrm{M}$
Bic was applied and the extracellular $\mathrm{Mg}^{2+}$ concentration was reduced (to $0.1 \mathrm{~mm}$ ), these neurons exhibited spontaneous depolarization and repetitive firing (Fig. 8C2). The faster sweep records in Figure 8C3 clearly illustrate that the depolarizations were synchronous in this pair, although the generation of individual action potentials was not always synchronized (C4). Because these neurons were not directly connected with the other, the present results suggest that the neuronal population to which they belong may (1) exhibit spontaneous fluctuations in membrane potential and (2) be synchronously depolarized. Similar results were observed in 10 pairs of SGI neurons that did not show direct synaptic contact. Synchronous depolarization was observed even when the generation of $\mathrm{Na}^{+}$spikes was blocked by intracellular application of $5 \mathrm{~mm}$ QX-314 $(n=15)$ (Fig. 9A,B). Even in a pair of SGI neurons that exhibited small fluctuations in membrane potential in control solution (similar to Fig. $8 \mathrm{C1}$ ), application of $10 \mu \mathrm{M}$ Bic plus low $\mathrm{Mg}^{2+}$ induced a large and synchronized depolarization (Fig. 9A). Phase plots (Fig. 9B1,2) clearly illustrated that these two neurons changed their membrane potentials synchronously. The correlation between the membrane potentials of these two neurons was analyzed using the plots of normalized membrane potentials (Fig. 9B2), and the correlation coefficient was found to be high (mean $\pm \mathrm{SD}, 0.79 \pm$ 0.09 ; range, $0.64-0.92 ; n=7$ ). Synchronized depolarization was still observed after intracellular application of $30 \mathrm{~mm}$ BAPTA $(n=7)$ (Fig. 9C1). In contrast, application of $50 \mu \mathrm{M}$ D-APV eliminated both the spontaneous fluctuation and the synchronization (Fig. 9C2), and each recovered after washing out D-APV (data not shown). These results show that, whereas synchronized depolarization does not require $\mathrm{Ca}^{2+}$-dependent mechanisms, it is dependent on synaptic transmission mediated by NMDA receptors, in common with the long-lasting depolarization induced by LSO stimulation.

Finally, to test whether the neuronal mechanisms needed for synchronized depolarization can be triggered by an excitatory synaptic input, we recorded synaptic responses from a pair of SGI neurons after SGS stimulation. In control solution, SGS stimulation induced only short-lasting EPSPs in both SGI neurons (data not shown). The same SGS stimulation induced a repetition of the depolarization after application of $50 \mu \mathrm{M}$ Bic plus low $\mathrm{Mg}^{2+}$ (Fig. 9D). Similar results were obtained in eight pairs. These results suggest that neuronal mechanisms inducing synchronous depolarization in a population of SGI neurons underlie the nonlinear amplification shown by SGI neurons in response to visual inputs from the superficial layers.

\section{Discussion}

In the present study, on SC slices from young and adult rats, we found that processes confined to the intermediate gray layer are sufficient for evoking long-lasting depolarization and highfrequency repetitive firing, and that these responses are unmasked by $\mathrm{GABA}_{\mathrm{A}}$ receptor antagonists and are crucially dependent on synaptic transmission mediated by NMDA receptors.

\section{Inhibitory neurons suppressing burst activities}

In the present slices, tonic inhibition from $\mathrm{SNr}$, which is active under in vivo conditions, has been removed. Furthermore, tonic inhibition from $\mathrm{rSC}$, which is also active in vivo, also may be mostly removed. Thus, much of the tonic inhibition affecting SGI neurons in vivo may be removed when the SC is sliced, and release from inhibition by local inhibitory neurons may be necessary for long-lasting depolarization and burst firing responses in SGI neurons to be induced by synaptic inputs from the SGS or OT. 

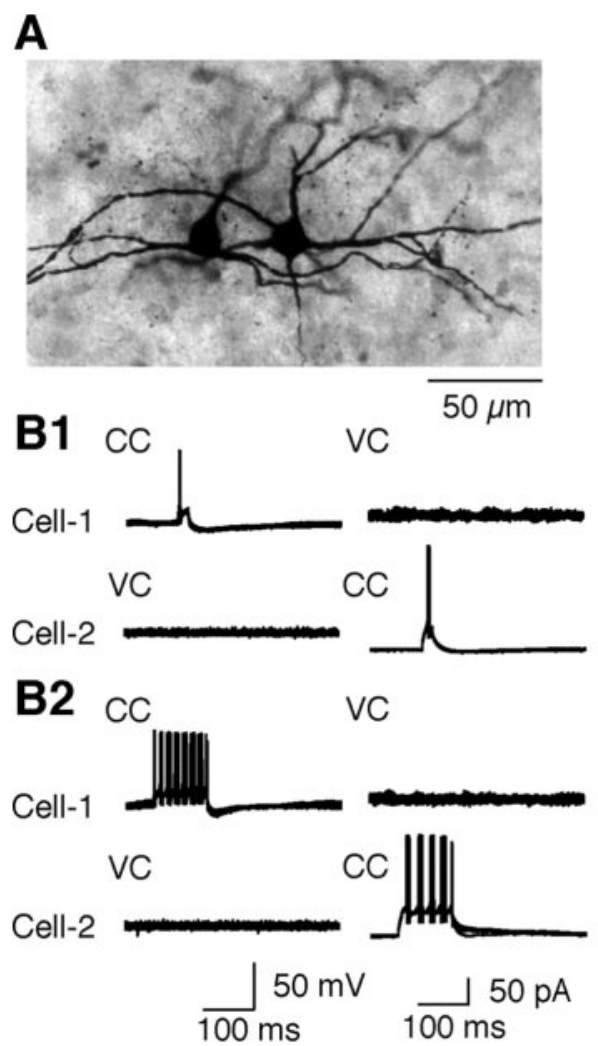

\section{1 Control}

Cell-1

Cell-2
$-72 \mathrm{mV}$

$79 \mathrm{mV}$

\section{Bic + low $\mathrm{Mg}^{2+}$}

Cell-1
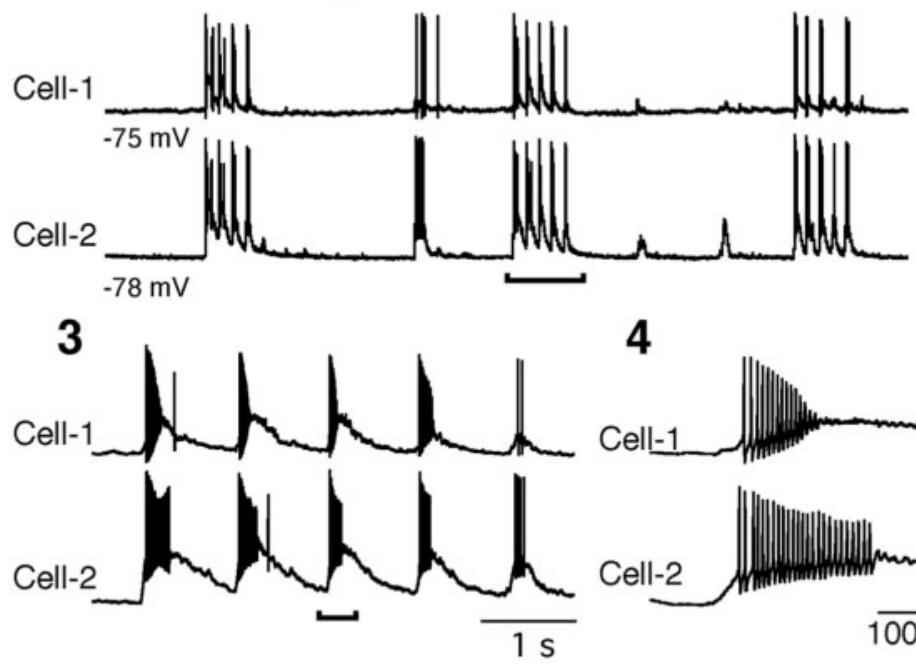

4

\section{Wash}

Cell-1

Cell-2

$$
-72 \mathrm{mV}
$$

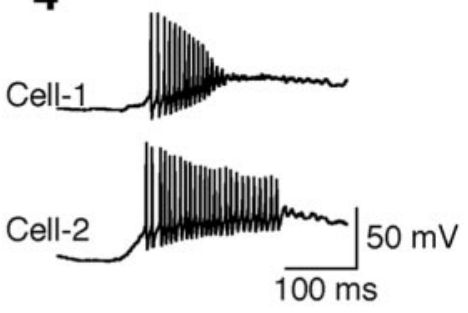

$100 \mathrm{~ms}$

$$
-74 \mathrm{mV}
$$

Figure 8. Simultaneous recordings from a pair of SGI neurons. A, Photomicrograph of the pair of recorded SGI neurons (injected with biocytin intracellularly). $B$, Recordings of current responses from one cell in voltage-clamp mode (VC) after induction of a single ( 1) or several ( 2 ) action potential(s) in the other cell by current injection in current-clamp mode (CC). C, Spontaneous membrane potentials in control solution (1), in the presence of $10 \mu \mathrm{m}$ Bic and low (0.1 mm) Mg ${ }^{2+}(2)$, and after washing out Bic and low Mg ${ }^{2+}$ (5). C3, Faster-sweep records of segments underlined in C2. C4, Faster-sweep records of segment underlined in C3.

The question then arises, How are the local inhibitory neurons activated? In the present study, we could observe spontaneous IPSCs in SGI neurons in vitro (Fig. 4), suggesting that they exhibit spontaneous firing even in slice preparations. In addition, voltage-clamp experiments revealed that stimulation of LSO or SGS induced polysynaptic IPSCs in SGI neurons. These results suggest that the excitatory pathway from OT to SGI activates GABAergic neurons in the SC. Such inhibition appears to function as either feedforward or recurrent inhibition. The existence of recurrent inhibition on output neurons in the deeper layers has been demonstrated in rabbits by Zhu and Lo (2000). Such feedforward/recurrent inhibition may curtail the preceding EPSPs and prevent the maintenance of depolarization in SGI neurons in response to inputs arriving via the interlaminar connection.

The next question is, Where are the inhibitory neurons located in the SC? Immunocytochemical studies have revealed that, in the SC, GABA- or GAD-immunoreactive neurons are densely distributed in the SGS, and that the density is lower in the deeper layers (Ottersen and Storm-Mathisen, 1984; Mize, 1988; Mize et al., 1991). Thus, one possibility is that GABAergic neurons in SGS contribute to the inhibition of SGI neurons. In the present study, however, monosynaptic IPSCs were not induced in most SGI neurons by SGS stimulation applied at a site dorsal to the recorded cell. This suggests that inhibitory neurons in the deeper layers, and not in the SGS, are responsible for the inhibition of SGI neurons.
The third question is, How is the local inhibition regulated? The observation of spontaneous IPSCs in slices suggests the possibility that local inhibitory neurons may exhibit tonic activity in vivo, although the existence of deeper-layer neurons in the caudal SC that are both tonically active and pause before saccades has not been established in in vivo studies, presumably because of the small size of GABAergic interneurons in the SC (Mize et al., 1991). In addition, a recent study in our laboratory has shown that cholinergic inputs to the SGI selectively suppress GABAergic transmission to SGI neurons through an activation of presynaptic M1-type muscarinic receptors (Lee et al., 2002). These may be a candidate neuronal element for the selective regulation of inhibitory synaptic transmission in the SGI.

\section{Bursting mechanism in SGI neurons}

The present study has shown that an intrinsic property of individual SGI neurons is not the main factor in the generation of long-lasting depolarization and repetitive firing in SGI neurons after application of a $\mathrm{GABA}_{\mathrm{A}}$ receptor antagonist. Because Bic blocks the SK-type calcium-activated potassium channels that underlie afterhyperpolarization (Johnson and Seutin, 1997; Debarbieux et al., 1998; Khawaled et al., 1999), it was possible that the drastic enhancement of EPSPs seen in SGI neurons after application of Bic might not have been attributable to its effect on the $\mathrm{GABA}_{\mathrm{A}}$ receptor, but to its effect on calcium-activated potassium channels. However, long-lasting depolarization and repet- 
A Bic + low $\mathrm{Mg}^{2+}$

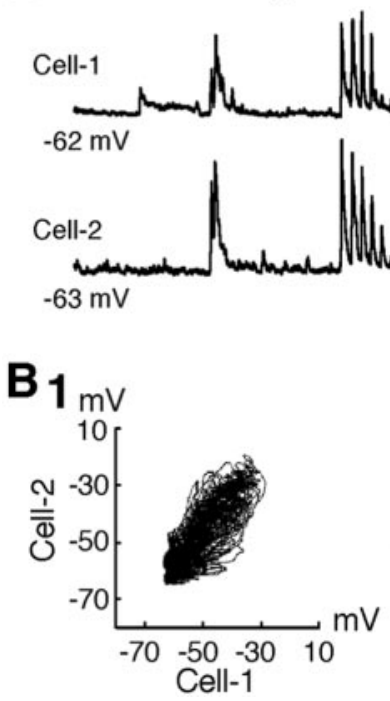

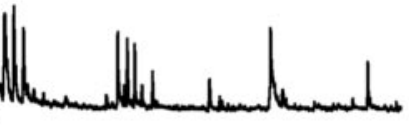

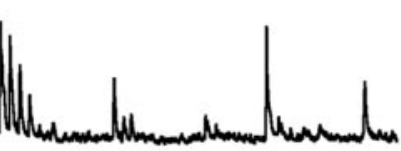
$20 \mathrm{mV}$

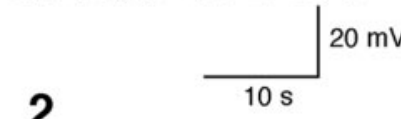

2

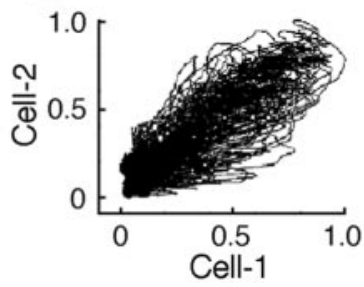

C 1 Bic + low $\mathrm{Mg}^{2+}$

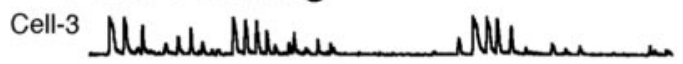

Cell-4 Mrumunum Non

$2 \mathrm{Bic}+$ low $\mathrm{Mg}^{2+}+$ APV

Cell-3

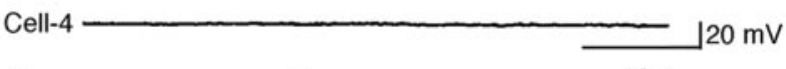

D Bic + low $\mathrm{Mg}^{2+}$ SGS stim. $50 \mu \mathrm{A}$

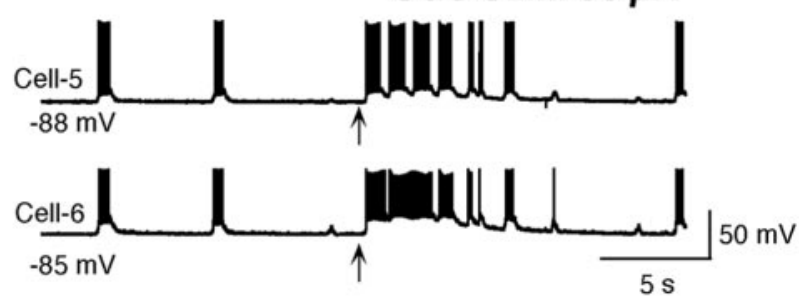

Figure 9. A, Spontaneous membrane potentials recorded simultaneously from a pair of SGI neurons (cell- 1 and cell-2) in the presence of $10 \mu \mathrm{m} \mathrm{Bic} \mathrm{and} \mathrm{low} \mathrm{(0.1} \mathrm{mm)} \mathrm{Mg}{ }^{2+}$. The intracellular solution contained $5 \mathrm{~mm}$ QX-314. B, Plots of membrane potentials ( 1) and normalized membrane potentials (2) for cell-1 against cell-2. C, Spontaneous membrane potentials recorded simultaneously from a pair of SGI neurons (cell-3 and cell-4) in the presence of $10 \mu \mathrm{m}$ Bic and low (0.1 mm) Mg ${ }^{2+}(1)$, and after application of $50 \mu \mathrm{m}$ APV (2). The intracellular solution contained $5 \mathrm{~mm}$ QX-314 plus $30 \mathrm{~mm}$ BAPTA. D, Simultaneous recordings of synaptic responses from a pair of SGI neurons (cell-5 and cell-6) after stimulation of the SGS (arrow) in the presence of $10 \mu \mathrm{m}$ Bic and low $(0.1 \mathrm{~mm}) \mathrm{Mg}^{2+}$. The intracellular solution did not contain QX-314.

itive firing was also seen when we used another $\mathrm{GABA}_{\mathrm{A}}$ receptor antagonist [SR95531, which does not affect afterhyperpolarization (Seutin et al., 1997)] instead of Bic. Thus, a nonspecific effect of Bic is unlikely to explain the induction of long-lasting depolarization and repetitive firing.

The present study has demonstrated that the neuronal mechanisms sufficient for burst generation exist in a local circuit within a relatively small region of SGI. This supports the finding of Pettit et al. (1999) that repetitive firing of SGI neurons can be induced by localized laser photolysis of caged glutamate. They concluded that the bursting activity was induced by local excitatory circuits within the SGI. These findings lend additional experimental support to the previous proposal that local excitatory interactions within the deeper layers underlie burst generation in SGI neurons (Moschovakis et al., 1988a,b; Bozis and Moschovakis, 1998). The difference in synaptic responses to LSO stimulation between SGS and SGI neurons suggests that local excitatory circuits unique to SGI amplify and prolong the synaptic inputs to SGI neurons when $\mathrm{GABA}_{\mathrm{A}}$ receptor-mediated inhibition is reduced. This may be supported by the observation that synchronized depolarization occurred in SGI neurons on stimulation of SGS. Previously, Istvan and Munoz (1997) reported that pairs of adjacent saccadic-burst neurons showed synchronous firing during presaccadic burst activities, suggesting that the mechanism responsible for the generation of the synchronous depolarizations seen in the present study shares a common mechanism with the presaccadic bursts seen in vivo.

Anatomical evidence for local excitatory connections has been provided for TTLBs in the monkey (Moschovakis et al., 1988b). In the cat, however, orienting-related neurons that project to the reticular formation [namely, tectoreticulo(spinal) neurons (TR(S)Ns)] (Guitton and Munoz, 1991; Munoz et al., 1991) have not been shown to emit recurrent collaterals (Grantyn and Grantyn, 1982; Grantyn and Berthoz, 1985; Karabelas and Moschovakis, 1985; Moschovakis and Karabelas, 1985; Olivier et al., 1993). Therefore, it may be claimed that, in cat, it is likely that the presaccadic burst is not caused by local excitatory interactions. However, our findings that synchronous depolarizations occur in pairs of SGI neurons that are not in direct contact with each other suggest that local excitatory interactions are not limited to burst neurons that have recurrent collaterals. Additive elements such as local excitatory neurons may exist in the deeper layer and interact to generate bursts that are conveyed to output neurons such as TR(S)Ns. Because local excitatory neurons may not be large, they might have been missed in previous in vivo studies.

\section{Role of NMDA receptors in burst generation}

The present study has shown that NMDA receptor-dependent synaptic transmission in a local excitatory network underlies the burst responses seen in SGI neurons. NMDA receptors are blocked by $\mathrm{Mg}^{2+}$ in a voltage-dependent manner and exhibit a J-shaped current-voltage relationship (Mayer et al., 1984; Nowak et al., 1984). This property may contribute to a nonlinear amplification of excitatory synaptic inputs that may in turn lead to burst generation in the neuronal population making up the SC local circuits. The importance of NMDA receptors has been stressed in the integration of multimodal responses in the deep layers of the SC (Binns and Salt, 1996), and the above results together strongly suggest that NMDA receptors are essential for the generation of bursting activity in SGI neurons.

\section{Fundamental structure of local circuits in SGI}

On the basis of the present study, we propose the fundamental structure and regulatory mechanism represented schematically in Figure 10 for the SC local circuit. When animals fixate their eyes (Fig. 10A), the SGI undergoes tonic inhibition by GABAergic neurons located outside and inside the SC. Before and during a saccade (Fig. 10B), the GABAergic inhibition is released, and the local excitatory connections among SGI neurons are activated, with the result that bursting commands are generated and sent to the brainstem saccade generator. This mechanism most likely serves to substantiate the threshold effects for the decision 
A Control
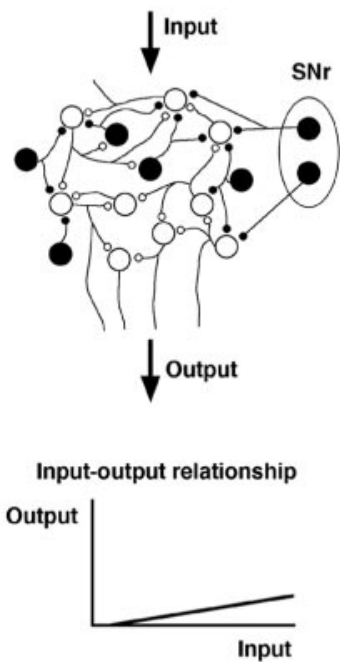

B Bicuculline
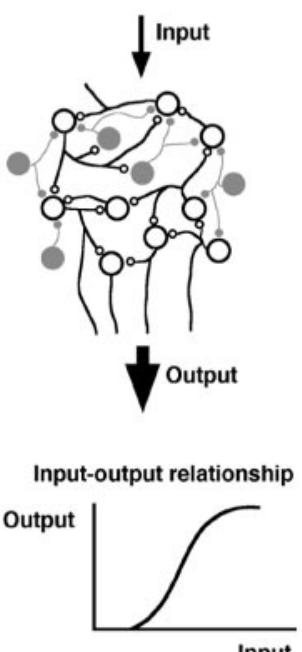

Figure 10. Schematic drawing of proposed local mechanism for the generation of burst responses after release from GABAergic inhibition. Large open and filled circles indicate excitatory and inhibitory neurons, respectively. Small circles indicate terminal boutons.

to initiate saccadic responses after target selection and/or target prediction, which has been shown to take place in the deeper layers of the SC (Glimcher and Sparks, 1992; Dorris et al., 1997). The main points of our scheme have already been proposed on theoretical grounds by Bozis and Moschovakis (1998). However, our scheme puts more stress on the role of local inhibitory interneurons as an addition to the inhibition originating from the substantia nigra than the model proposed by the previous authors. Although our findings were obtained in experiments on a rat in vitro system and should have limitation in generalization to other mammalian species, we believe that they model an in vivo phenomenon that is linked to eye movements in mammals.

\section{References}

Behan M, Appell PP (1992) Intrinsic circuitry in the cat superior colliculus: projection from the superficial layers. J Comp Neurol 315:230-243.

Binns KE, Salt TE (1996) Importance of NMDA receptors for multimodal integration in the deep layers of the cat superior colliculus. J Neurophysiol 75:920-930.

Bozis A, Moschovakis AK (1998) Neural network simulations of the primate oculomotor system. III. An one-dimensional, one-directional model of the superior colliculus. Biol Cybern 79:215-230.

Dean P, Redgrave P, Westby GW (1989) Event or emergency? Two response systems in the mammalian superior colliculus. Trends Neurosci $12: 137-147$

Debarbieux F, Brunton J, Charpak S (1998) Effect of bicuculline on thalamic activity: a direct blockade of IAHP in reticularis neurons. J Neurophysiol 79:2911-2918.

Dorris MC, Paré M, Munoz DP (1997) Neuronal activity in monkey superior colliculus related to the initiation of saccadic eye movements. J Neurosci 17:8566-8579.

Glimcher PW, Sparks DL (1992) Movement selection in advance of action in the superior colliculus. Nature 355:542-545.

Grantyn A, Berthoz A (1985) Burst activity of identified tectoreticulo-spinal neurons in the alert cat. Exp Brain Res 57:417-421.

Grantyn A, Grantyn R (1982) Axonal patterns and sites of termination of cat superior colliculus neurons projecting to the tecto-bulbo-spinal tract. Exp Brain Res 46:243-256.

Grantyn R, Ludwig R, Eberhardt W (1984) Neurons of the superficial tectal gray. An intracellular HRP-study on the kitten superior colliculus in vitro. Exp Brain Res 55:172-176.

Guitton D, Munoz DP (1991) Control of orienting gaze shifts by the tectoreticulospinal system in the head-free cat. I. Identification, localization, and effects of behavior on sensory responses. J Neurophysiol 66:1605-1623.
Hall WC, Lee P (1993) Interlaminar connections of the superior colliculus in the tree shrew. I. The superficial gray layer. J Comp Neurol 332:213-223.

Hikosaka O, Wurtz RH (1983a) Visual and oculomotor functions of monkey substantia nigra pars reticulata. I. Relation of visual and auditory responses to saccades. J Neurophysiol 49:1230-1253.

Hikosaka O, Wurtz RH (1983b) Visual and oculomotor functions of monkey substantia nigra pars reticulata. III. Memory-contingent visual and saccade responses. J Neurophysiol 49:1268-1284.

Hikosaka O, Wurtz RH (1983c) Visual and oculomotor functions of monkey substantia nigra pars reticulata. IV. Relation of substantia nigra to superior colliculus. J Neurophysiol 49:1285-1301.

Horn AK, Buttner-Ennever JA, Wahle P, Reichenberger I (1994) Neurotransmitter profile of saccadic omnipause neurons in nucleus raphe interpositus. J Neurosci 14:2032-2046.

Isa T, Endo T, Saito Y (1998) The visuo-motor pathway in the local circuit of the rat superior colliculus. J Neurosci 18:8496-8504.

Isa T, Endo T, Saito Y (1999) Neural mechanisms substantiating non-linear activation property of local circuits in the intermediate layer of rat superior colliculus. Soc Neurosci Abstr 25:1919.

Istvan PJ, Munoz DP (1997) Neuronal connectivity in monkey superior colliculus during saccades: evidence from multiple recordings and cross correlation analysis. Soc Neurosci Abstr 23:1296.

Johnson SW, Seutin V (1997) Bicuculline methiodide potentiates NMDAdependent burst firing in rat dopamine neurons by blocking apaminsensitive $\mathrm{Ca}^{2+}$-activated $\mathrm{K}^{+}$currents. Neurosci Lett 231:13-16.

Karabelas AB, Moschovakis AK (1985) Nigral inhibitory termination on efferent neurons of the superior colliculus: an intracellular horseradish peroxidase study in the cat. J Comp Neurol 239:309-329.

Katsuta H, Isa T (2003) Release from $\mathrm{GABA}_{\mathrm{A}}$ receptor-mediated inhibition unmasks interlaminar connection within superior colliculus in anesthetized adult rats. Neurosci Res 46:73-83.

Khawaled R, Bruening-Wright A, Adelman JP, Maylie J (1999) Bicuculline block of small-conductance calcium-activated potassium channels. Pflügers Arch 438:314-321.

Lee P, Hall WC (1995) Interlaminar connections of the superior colliculus in the tree shrew. II: Projections from the superficial gray to the optic layer. Vis Neurosci 12:573-588.

Lee PH, Helms MC, Augustine GJ, Hall WC (1997) Role of intrinsic synaptic circuitry in collicular sensorimotor integration. Proc Natl Acad Sci USA 94:13299-13304.

Lee F, Endo T, Isa T (2002) Muscarinic inhibition of GABAergic transmission in the superior colliculus. Neurosci Res [Suppl] 26:S58.

MacDermott AB, Mayer ML, Westbrook GL, Smith SJ, Barker JL (1986) NMDA-receptor activation increases cytoplasmic calcium concentration in cultured spinal cord neurones. Nature 321:519-522.

Mayer ML, Westbrook GL, Guthrie PB (1984) Voltage-dependent block by $\mathrm{Mg}^{2+}$ of NMDA responses in spinal cord neurones. Nature 309:261-263.

Meredith MA, Ramoa AS (1998) Intrinsic circuitry of the superior colliculus: pharmacophysiological identification of horizontally oriented inhibitory interneurons. J Neurophysiol 79:1597-1602.

Mize RR (1988) Immunocytochemical localization of $\gamma$-aminobutyric acid (GABA) in the cat superior colliculus. J Comp Neurol 276:169-187.

Mize RR, Jeon CJ, Hamada OL, Spencer RF (1991) Organization of neurons labeled by antibodies to $\gamma$-aminobutyric acid (GABA) in the superior colliculus of the rhesus monkey. Vis Neurosci 6:75-92.

Mooney RD, Nikoletseas MM, Hess PR, Allen Z, Lewin AC, Rhoades RW (1988) The projection from the superficial to the deep layers of the superior colliculus: an intracellular horseradish peroxidase injection study in the hamster. J Neurosci 8:1384-1399.

Moschovakis AK, Karabelas AB (1985) Observations on the somatodendritic morphology and axonal trajectory of intracellularly HRP-labeled efferent neurons located in the deeper layers of the superior colliculus of the cat. J Comp Neurol 239:276-308.

Moschovakis AK, Karabelas AB, Highstein SM (1988a) Structure-function relationships in the primate superior colliculus. I. Morphological classification of efferent neurons. J Neurophysiol 60:232-262.

Moschovakis AK, Karabelas AB, Highstein SM (1988b) Structure-function relationships in the primate superior colliculus. II. Morphological identity of presaccadic neurons. J Neurophysiol 60:263-302. 
Munoz DP, Istvan PJ (1998) Lateral inhibitory interactions in the intermediate layers of the monkey superior colliculus. J Neurophysiol 79:1193-1209.

Munoz DP, Wurtz RH (1993) Fixation cells in monkey superior colliculus. I. Characteristics of cell discharge. J Neurophysiol 70:559-575.

Munoz DP, Wurtz RH (1995) Saccade-related activity in monkey superior colliculus. I. Characteristics of burst and buildup cells. J Neurophysiol 73:2313-2333.

Munoz DP, Guitton D, Pelisson D (1991) Control of orienting gaze shifts by the tectoreticulospinal system in the head-free cat. III. Spatiotemporal characteristics of phasic motor discharges. J Neurophysiol 66:1642-1666.

Nowak L, Bregestovski P, Ascher P, Herbet A, Prochiantz A (1984) Magnesium gates glutamate-activated channels in mouse central neurones. Nature 307:462-465.

Olivier E, Grantyn A, Chat M, Berthoz A (1993) The control of slow orienting movements by tecto-reticulo-spinal neurons in the cat: behavior, discharge patterns and underlying connections. Exp Brain Res 93:435-449.

Ottersen OP, Storm-Mathisen J (1984) Glutamate- and GABA-containing neurons in the mouse and rat brain, as demonstrated with a new immunocytochemical technique. J Comp Neurol 229:374-392.

Özen G, Augustine GJ, Hall WC (2000) Contribution of superficial layer neurons to premotor bursts in the superior colliculus. J Neurophysiol $84: 460-471$.

Partridge LD, Müller TH, Swandulla D (1994) Calcium-activated nonselective channels in the nervous system. Brain Res Rev 19:319-325.

Pettit DL, Helms MC, Lee P, Augustine GJ, Hall WC (1999) Local excitatory circuits in the intermediate gray layer of the superior colliculus. J Neurophysiol 81:1424-1427.

Rhoades RW, Mooney RD, Rohrer WH, Nikoletseas MM, Fish SE (1989) Organization of the projection from the superficial to the deep layers of the hamster's superior colliculus as demonstrated by the anterograde transport of Phaseolus vulgaris leucoagglutinin. J Comp Neurol 283:54-70.
Robinson DA (1972) Eye movements evoked by collicular stimulation in the alert monkey. Vision Res 12:1795-1808.

Saito Y, Isa T (1999) Electrophysiological and morphological properties of neurons in the rat superior colliculus. I. Neurons in the intermediate layer. J Neurophysiol 82:754-767.

Saito Y, Isa T (2000) Voltage-gated transient outward currents in neurons with different firing patterns in rat superior colliculus. J Physiol (Lond) 528:91-105.

Schiller PH, Koerner F (1971) Discharge characteristics of single units in superior colliculus of the alert rhesus monkey. J Neurophysiol 34:920-936.

Schiller PH, Stryker M (1972) Single-unit recording and stimulation in superior colliculus of the alert rhesus monkey. J Neurophysiol 35:915-924.

Seutin V, Scuvee-Moreau J, Dresse A (1997) Evidence for a non-GABAergic action of quaternary salts of bicuculline on dopaminergic neurones. Neuropharmacology 36:1653-1657.

Sparks DL (1986) Translation of sensory signals into commands for control of saccadic eye movements: role of primate superior colliculus. Physiol Rev 66:118-171.

Sparks DL, Mays LE (1980) Movement fields of saccade-related burst neurons in the monkey superior colliculus. Brain Res 190:39-50.

Sparks DL, Holland R, Guthrie BL (1976) Size and distribution of movement fields in the monkey superior colliculus. Brain Res 113:21-34.

Sparks D, Rohrer WH, Zhang Y (2000) The role of the superior colliculus in saccade initiation: a study of express saccades and the gap effect. Vision Res 40:2763-2777.

Wurtz RH, Albano JE (1980) Visual-motor function of the primate superior colliculus. Annu Rev Neurosci 3:189-226.

Wurtz RH, Goldberg ME (1972) Activity of superior colliculus in behaving monkey. III. Cells discharging before eye movements. J Neurophysiol 35:575-586.

Zhu JJ, Lo FS (2000) Recurrent inhibitory circuitry in the deep layers of the rabbit superior colliculus. J Physiol (Lond) 523:731-740. 